\title{
NEWS IN BRIEF
}

\section{EEC funds 10 new solar energy projects}

THE Commission of the European Communities approved last week grants to 10 new solar energy projects totalling 3 million EUA ( 1 EUA $=£ .665)$. The projects include an award of 53,000 EUA to K.U. Leuven of Belgium for an electric car using solar energy and nine awards to solar heating projects which include block central heating by solar power for 250 houses in Alpes-Maritime in France, solar heating of greenhouses in Italy, a West German project to study solar heating of swimming pools and a project for solar energy heating of phosphorising vats at a refrigerator production plant in Pordenone, Italy.

\section{UK locates geothermal energy source}

AN exploratory borehole at Marchwood, near Southampton has located a large deposit of water at a temperature of $70^{\circ} \mathrm{C}$ the Secretary of State announced in Parliament last week. The water was found at a depth of 5,600 feet and can be brought to the surface at a temperature of $65^{\circ} \mathrm{C}$ a drop of only $5^{\circ} \mathrm{C}$. There is sufficient water in the well to heat about 1000 houses over a period of several decades. Pumps will be installed late this summer to bring the water to the surface and its mineral content is being assessed.

Geothermal energy has been in use in Hungary since the beginning of the 20th century and has found increasing uses in France to heat apartment blocks in the Paris suburbs. France plans to have half a million geothermally heated buildings by 1990 which will produce a $15 \%$ saving in running costs. The UK's $£ 1.8$ million

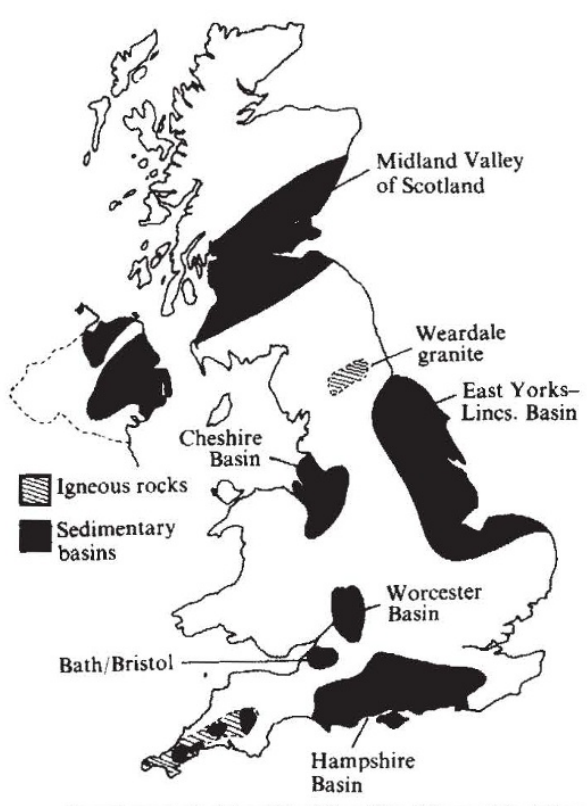

borehole project is part of a $£ 11$ million yearly programme to explore alternative energy sources including wave, wind, tidal and solar energy.

\section{UK Seveso report issued}

AN English translation of the 1978 Italian Parliamentary Commission report on the Seveso accident was published by the UK Health and Safety Executive last week. The Executive clearly feels that the Seveso accident involving the discharge from a chemical factory of some $250-500$ grams of 2, 3, 7, 8-tetrachlorodibenzo-p-dioxin (dioxin) over a populated area was serious enough to warrant a report of the causes and consequences of the incident being made more widely available. But central to the concern over the health of the Seveso residents was the two week delay in ordering their evacuation from the dioxincontaiminated area: on this point the report has been criticised as inaccurate. For a detailed discussion see Nature 22 February 1979, page 588.

Seveso: A translation by the Health and Safety Executive of the official report of the (Italian) Parliamentary Commission of Enquiry. $\$ 25.00$

\section{Queen's Award to new, safe insecticide}

A GROUP of UK scientists received a Queen's Award last week for their development of a class of highly active insecticides that have low mammalian toxicity. Chemists and biologists at the Rothamsted Experimental Station solved the problem of making synthetic pyrethroid compounds, known from the group's previous research to attack insect but not mammalian nervous systems, stable against exposure to sunlight. According to Paul Needham of the Rothamsted Station the compounds breakdown rapidly in soil and residues are unlikely to accumulate to contaminate the environment. Three compounds of the new class of insecticides, permethrin, cypermethrin, and decamethrin, are sufficiently active to be used at dosages of an oder of magnitude less $(10-200 \mathrm{~g} / \mathrm{ha})$ than that of most other insecticides $(500-1500 \mathrm{~g} / \mathrm{ha})$. The pyrethroids are effective against lepidopterous larvae in cotton, timber, wool and stored products.

\section{Collection of Yeast Cultures finds home}

THE UK National Collection of Yeast Cultures, threatened by withdrawal of funds by two of its sponsors last January (Nature, 24 January page 325) will be moved to the Agricultural Research Council's Food Research Institute in Norwich before the end of the year. The Collection, consisting of 1,500 yeast strains widely used throughout Europe was saved by a decision of the Advisory Board for the Research Councils to provide the money to move and maintain the collection. The ABRC will provide about $£ 24,000$ annually so that the Collection can carry out its central functions of maintaining and supplying fully characterised yeast cultures to industry, universities and schools as well as acting as a reference and information centre for identification and deposit of yeast cultures. The collection will continue to be housed in its present quarters, the Brewery Research Foundation, until the transfer is effected during the summer.

\section{Research could help industry: Canadian report}

INCREASED support for basic research in areas such as materials science and processing, vehicle control systems and battery electrochemistry could provide a long-term boost to the Canadian car industry, according to a report prepared by Arthur D Little of Canada Ltd for the Ministry of State for Science and Technology.

The report, prepared on parallel lines to an initiative (already under way) of the US government to stimulate research through projects jointly supported by federal and industry funding, lists a number of areas of "directed basic research opportunities" relevant to automotive technology which might be performed in universities or research institutes. "This kind of research is not directly intended to result in the design of new vehicles, engines, or components; it is meant to focus on achieving a fuller understanding of the physical and chemical processes underlying vehicle technology,"' the report says. But it adds that programmes of this nature, with a time horizon for commercialisation primarily in the 10 to 20 year range, must receive adequate government funding in order to be successful. "There are a large number of government sponsored research programmes in Canadian universities and government research centres that we believe are underfunded," the report says.

\section{Errata}

IN the leader of 17 April, page 583 David Howell was erroneously referred to as the UK opposition spokesman on energy. This should have been David Owen.

The letter from John Goddier in 24 April, page 658 was written in his capacity as Branch secretary of the Agricultural Research Council Branch Institution of Professional Civil Servants. It does not represent an official ARC view. 